\title{
Amygdala Neural Encoding of the Absence of Reward during Extinction
}

\author{
Kay M. Tye, ${ }^{1 \star}$ Jackson J. Cone, ${ }^{1 \star}$ William W. Schairer, ${ }^{1}$ and Patricia H. Janak ${ }^{1,2,3}$ \\ ${ }^{1}$ Ernest Gallo Clinic and Research Center, University of California at San Francisco, Emeryville, California 94608, and ${ }^{2}$ Department of Neurology and \\ ${ }^{3}$ Wheeler Center for the Neurobiology of Addiction, University of California at San Francisco, San Francisco, California 94143
}

The basolateral amygdala complex (BLA) has been identified as a critical structure mediating fear extinction. However, little is known about the functional role of neurons in the BLA during the extinction of a reward-seeking behavior. Here, we used in vivo electrophysiology procedures in freely moving rats to investigate whether and how the BLA encodes the extinction of responding for sucrose. We recorded 330 neurons from 15 rats during a within-session extinction procedure following training under a partial reinforcement schedule. Several distinct populations of neurons change their response profiles as the rat ceases to respond for the omitted reinforcer. One population of neurons ( 32 of $330 ; 10 \%$ ), which responded selectively to port entries in the presence, but not the absence, of sucrose during maintenance, subsequently developed a phasic response to port entries in the absence of sucrose during the extinction epoch only. The relative proportion of these "reinforcement-omission" neurons per rat was correlated with response intensity during extinction, as well as with the rate at which reward-seeking behavior was extinguished. A subpopulation of neurons responded with opposite phasic changes in activity to port entries in the presence of sucrose and to port entries during extinction, demonstrating that BLA neurons may contribute to the detection of value differences between expected and actual outcomes. Another population of neurons (47 of 330; 14\%) responded to the empty port only during extinction. Because BLA neural correlates reflect the omission of an expected reward, these neuronal populations may contribute to the expression of behavior during extinction.

\section{Introduction}

Environmental contingencies for reward availability may change unexpectedly. Thus, the ability of an organism to quickly and appropriately adapt its behavior to a change in the environment is essential to survival. Furthermore, understanding the neural circuitry that mediates the extinction of a reward-seeking behavior is essential for improving therapeutic interventions for a variety of psychopathologies such as compulsive overeating or drug addiction.

Though extinction is likely mediated by a distributed neural network (Quirk and Mueller, 2008), several studies have implicated the basolateral amygdala (BLA) as a critical structure for fear extinction. Intra-BLA infusions of NMDAR antagonists, kinase inhibitors, or the $\mathrm{GABA}_{\mathrm{A}}$ agonist, muscimol, impair the acquisition of fear extinction (Falls et al., 1992; Lu et al., 2001; Lin et al., 2003; Sotres-Bayon et al., 2007). Although there is a rapidly accumulating literature describing the neural basis of fear extinction, little is known about the neural circuitry underlying the extinction of reward-seeking behavior.

In humans, functional magnetic resonance imaging (fMRI) studies demonstrate that the amygdala responds differently to

Received Aug. 27, 2009; revised 0ct. 28, 2009; accepted Nov. 10, 2009.

This research was supported by the State of California for Medical Research on Alcohol and Substance Abuse through the University of California at San Francisco (P.H.J.) and a National Science Foundation Graduate Research Fellowship (K.M.T.). We thank E. E. Steinberg, T. M. Gill, R. Keiflin, and R. Kapur for helpful comments.

*K.M.T. and J.J.C. contributed equally to this work.

Correspondence should be addressed to Kay M. Tye, Ernest Gallo Clinic and Research Center, University of California at

San Francisco, 5858 Horton Street, Suite 200, Emeryville, CA 94608. E-mail: kaytye@alum.mit.edu.

DOI:10.1523/JNEUROSCI.4240-09.2010

Copyright $\odot 2010$ the authors $\quad 0270-6474 / 10 / 300116-10 \$ 15.00 / 0$ reward receipt and omission (Ernst et al., 2005). In primates, single-unit recording within the amygdala has identified a subset of neurons that respond to reinforcer omission (Belova et al., 2007). The amygdala has been implicated in processing the distinction between stimuli that predict positive and negative hedonic outcomes in primates (Paton et al., 2006) and in rats (Schoenbaum et al., 1998; Saddoris et al., 2005). However, little is known about the relationship between amygdala neuron activity and the behavioral response to the unexpected omission of reward during the extinction of reward-seeking behavior.

Because the BLA is critically involved in processing outcome expectation (Schoenbaum et al., 1998; Corbit and Balleine, 2005; Belova et al., 2007), fear extinction (Repa et al., 2001; Myers and Davis, 2002; Herry and Mons, 2004; Herry et al., 2008; Likhtik et al., 2008; Quirk and Mueller, 2008; Ehrlich et al., 2009), and the expression and modulation of conditioned reward seeking (Cador et al., 1989; Baxter and Murray, 2002; Carelli et al., 2003; McLaughlin and See, 2003; McLaughlin and Floresco, 2007; Tye and Janak, 2007; Tye et al., 2008), we hypothesized that BLA neurons encode the change in outcome expectation that underlies the extinction of reward-seeking behavior. To test this hypothesis, we recorded the activity of BLA neurons in vivo in freely moving rats during a within-session extinction procedure.

\section{Materials and Methods}

In vivo electrophysiological recordings. Male Sprague Dawley rats were bilaterally implanted with electrodes in the BLA to enable chronic neural recording during maintenance and extinction. Rats were anesthetized with isoflurane and stereotaxically implanted with fixed-wire electrode arrays (NeuroBiological Laboratories), directed at the BLA (antero- 
A

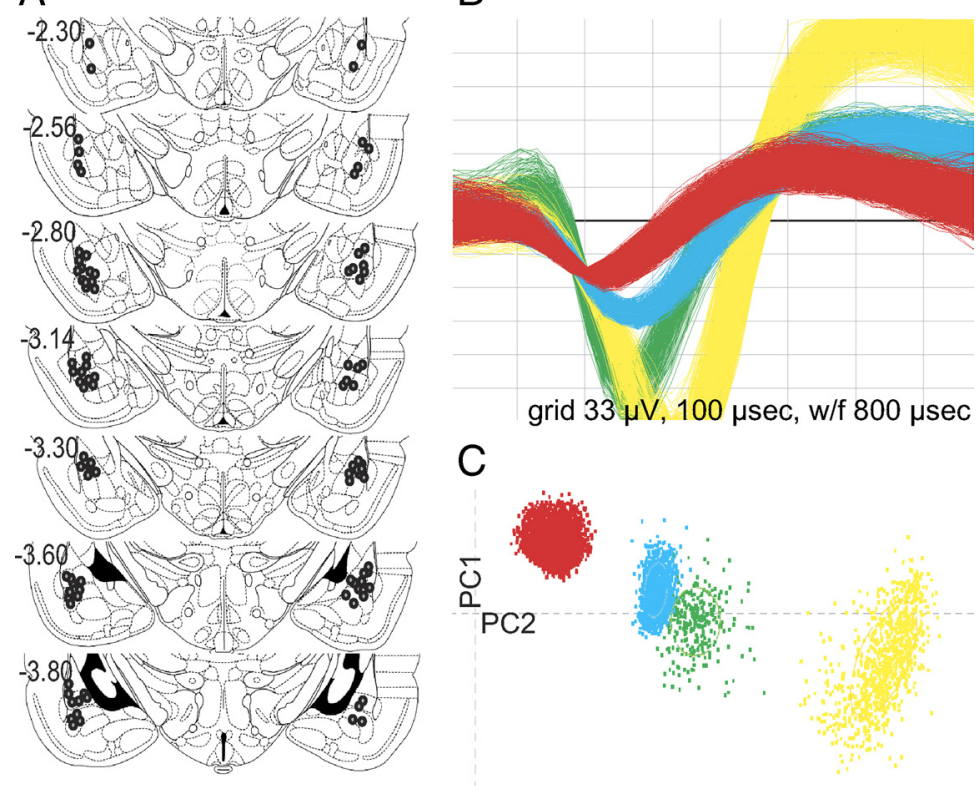

Figure 1. In vivo electrophysiological recording of basolateral amygdala neurons. $A$, Coronal diagrams showing chronic recording electrode tip placements (gray circles). Numbers on left indicate the anteroposterior coordinates caudal to bregma (Paxinos and Watson, 1998). $\boldsymbol{B}$, Representative waveforms from single units recorded from a single electrode tip located in the BLA. C, Corresponding cluster analysis for representative units isolated using principle component analysis. PC1, Principle component 1; $P C 2$, principle component 2.

posterior, -2.8 to -3.6 ; mediolateral, \pm 5.0 ; dorsoventral, -7.2 to $-7.5)$. Rats were allowed to heal for $5-10 \mathrm{~d}$, during which time they received food and water ad libitum. After healing, rats were food restricted to $90 \%$ of their ad libitum consumption for at least $24 \mathrm{~h}$ before initial training. All procedures were approved by the Gallo Center Institutional Animal Care and Use Committee and were in accordance with the National Institute of Health guidelines.

Behavioral training. Rats $(n=16)$ were trained to perform operant responses at a nosepoke (NP) operandum on a partial reinforcement schedule ( $\sim 50 \%$ of responses were reinforced) with a subsequent delivery (after $2 \mathrm{~s}$ ) of $0.1 \mathrm{ml}$ of a sucrose solution ( $15 \%$ sucrose in water) at an adjacent port. Rats were trained in three variations of the same behavioral procedure. The "reward-predictive cue" procedure was as follows: $\sim 50 \%$ of nosepokes were reinforced by a cue presentation followed by sucrose delivery during maintenance, with the cue omitted during extinction. The "random cue" procedure was as follows: $\sim 50 \%$ of nosepokes were reinforced with sucrose delivery only, with cues presented at random intervals. The "response-contingent cue" procedure was as follows: $\sim 50 \%$ of nosepokes were reinforced by a cue presentation and sucrose delivery during maintenance, with nosepokes reinforced only by the cue during extinction. For all groups, rats that did not reach learning criterion (at least 30 sucrose deliveries earned in a $2 \mathrm{~h}$ session) by the fourth session were excluded ( $n=1$ rat excluded, resulting in a final $n$ of 5 per group). All rats then received an additional posttraining "maintenance" session before the within-session extinction session. The withinsession extinction procedure consisted of $\sim 40 \mathrm{~min}$ of maintenance followed by a $1 \mathrm{~h}$ extinction epoch during which the sucrose reward was not available. Because there were no significant differences among the three groups in neural or behavioral activity, the data from these groups were pooled, unless otherwise indicated.

Histology. After the completion of the last session, animals were anesthetized with isoflurane and decapitated. A $19 \mu \mathrm{A}$ current was passed through each recording electrode that had identifiable single units. The brain was fixed in $10 \%$ formalin, $3 \%$ potassium ferrocyanide overnight. Brains were then submerged in $20 \%$ sucrose and $3 \%$ potassium ferrocyanide overnight. Potassium ferrocyanide was used to visualize and determine the location of each electrode tip. Brains were sectioned $(50 \mu \mathrm{m})$ throughout the extent of the amygdala. Alternating sections were stained with Neutral Red Nissl staining, allowing the visualization of the blue electrode placement marking in relation to the subnuclei of the amygdala. Serial sections were examined under a light microscope, and the location of each electrode tip was plotted on coronal sections taken from the rat stereotaxic atlas (Paxinos and Watson, 1998).

Single-unit recording and discrimination. Neural activity was recorded using commercial hardware and software, including headstage and programmable amplifiers, filters $(0.5$ and 5 $\mathrm{kHz}, 3 \mathrm{~dB}$ cutoffs), and multichannel spike sorting software (Plexon Instruments). Discrimination of individual units was performed off-line using principal component analysis of waveform shape. Single units were identified by constancy of waveform shape, crosscorrelogram, autocorrelogram, and interspike interval.

Analyzing neural response properties. Sorted files were processed in NeuroExplorer (Plexon Instruments) to extract unit timestamps and relevant reference event markers. Neural activity was characterized via perievent raster and perievent histogram analysis. NeuroExplorerextracted timestamps were then exported to MATLAB and analyzed for statistical significance of changes in phasic activity to various reference events. To determine whether a neuron altered firing during port entry, firing rate in each of five $100 \mathrm{~ms}$ bins following the reference event was compared with baseline firing rate during the $0.5 \mathrm{~s}$ baseline response window on a trial-by-trial basis using the nonparametric Wilcoxon signed-rank test. The baseline response window was determined on an individual rat-by-rat basis during which the animal had the least behavioral activity. Responses were deemed statistically significant if any $100 \mathrm{~ms}$ bins in the response window was statistically significant relative to the baseline epoch. Significant correlations with behavioral variables of interest (response intensity and extinction resistance) and neural activity surrounding the nosepoke operant response and the cue were not observed; thus the analyses reported here focus on reward delivery/port entry neural correlates. Categorization of neuronal types was confirmed by ensuring significant differences between port entry responses for a given neuron by comparing the three port entry conditions (sucrose port entry during maintenance, empty port entry during maintenance, and empty port entry during extinction) using the nonparametric ANOVA, the Friedman test. Significance was set at $p<0.01$. For the surface plots shown in Figures 5 and 6, the $Z$-score was calculated for each neuron on each trial for every $100 \mathrm{~ms}$ bin from $4 \mathrm{~s}$ before to $4 \mathrm{~s}$ after each port entry (PE), as follows: $Z_{\text {trial,bin }}=\mathrm{FR}_{\text {test bin }}-\mathrm{FR}_{\text {baseline avg }} / \mathrm{SD}_{\text {baseline, }}$, where $\mathrm{FR}_{\text {test bin }}$ is the firing rate of a neuron for each $100 \mathrm{~ms}$ bin in the response window, $\mathrm{FR}_{\text {baseline avg }}$ is the average firing rate per trial of each $100 \mathrm{~ms}$ bin within the baseline epoch, and $\mathrm{SD}_{\text {baseline }}$ is the $\mathrm{SD}$ of the firing rates of the $100 \mathrm{~ms}$ bins of the baseline epoch for each trial. These data were then used to construct the surface plots in MATLAB.

Behavioral analyses. The latency between each NP and the PE was calculated for each rat throughout the session. Early extinction was defined as the period between extinction onset and the first nosepoke-port entry trial for which the latency between the nosepoke and the subsequent port entry was $>2$ SDs from the mean (SDs and means were calculated for the entire session). Late extinction was defined as the period between the first trial for which the nosepoke-port entry latency was $>2$ SDs from the mean latency to the end of the session. Reinforced and nonreinforced nosepokes and port entries were tabulated in $10 \mathrm{~min}$ bins as depicted in Figure 2, $B$ and $C$. Total nonreinforced nosepokes and port entries were summed for the duration of the $60 \mathrm{~min}$ of extinction. The extinction slope was calculated using $10 \mathrm{~min}$ bins across $60 \mathrm{~min}$ of extinction. 
Response bout analysis. To quantitatively analyze bouts of behavioral responding, we used a parameter-based burst analysis method in NeuroExplorer with nosepoke response bouts defined as a minimum of two responses with an initial interevent interval $<1 \mathrm{~s}$ and a maximum interresponse interval of $60 \mathrm{~s}$ (Janak et al., 1998). Mean peak frequency was calculated by NeuroExplorer by using the minimum interevent interval between two responses per bout averaged across bouts.

Statistical analyses. All correlations were calculated using Pearson's correlation test. For all scatter plots used for correlational analysis where the relative proportion of neurons within a given response profile category was plotted on the $y$-axis, only rats with $n \geq 8$ total recorded neurons were included, resulting in the exclusion of two rats from these plots. Differences in the probability of behavioral responses following a nosepoke or port entry in early and late extinction were calculated using $\chi^{2}$ tests.

\section{Results}

We recorded a total of 330 BLA neurons across 15 adult male rats (Fig. 1). After recovery, rats were trained to respond at a nosepoke operandum on a partial $(50 \%)$ reinforcement schedule for sucrose delivered to an adjacent port (Fig. $2 \mathrm{~A}$ ). During maintenance, when reward was available to be earned, the partial reinforcement schedule enabled comparison of neural responses for rewarded and nonrewarded port entries. After five training sessions, rats underwent within-session extinction wherein nosepoke responses had no consequence and sucrose deliveries were unavailable (Fig. 2). Note that although the presence of a reward-predictive cue was varied across the three experimental groups, no significant differences were observed among the reward-predictive cue, random cue, and response-contingent cue groups for nosepoke responses (Fig. $2 B$ ) or port entries (Fig. 2C) during maintenance and extinction (repeated-measures ANOVA, all $F$ values $<2.0$, all $p$ values $>0.16$ ), and therefore the subjects were pooled for subsequent analyses.

\section{Extinction resistance increases with response intensity}

Despite some behavioral variability, rats typically displayed a distinct change in the pattern of nosepoke responding upon extinction onset (Fig. 3A). During maintenance, responding at the nosepoke operandum was steady and continuous (Fig. $3 A$ ). In contrast, upon extinction onset, the rate of responding at both the nosepoke operandum and the reward port became irregular and was characterized by discrete bouts of responding (Fig. 3A). To quantify the intensity of nosepoke responding, the peak frequency (Fig. $3 A$, inset) from each bout of responding was averaged to find the mean peak frequency. The mean peak frequency during extinc-

A

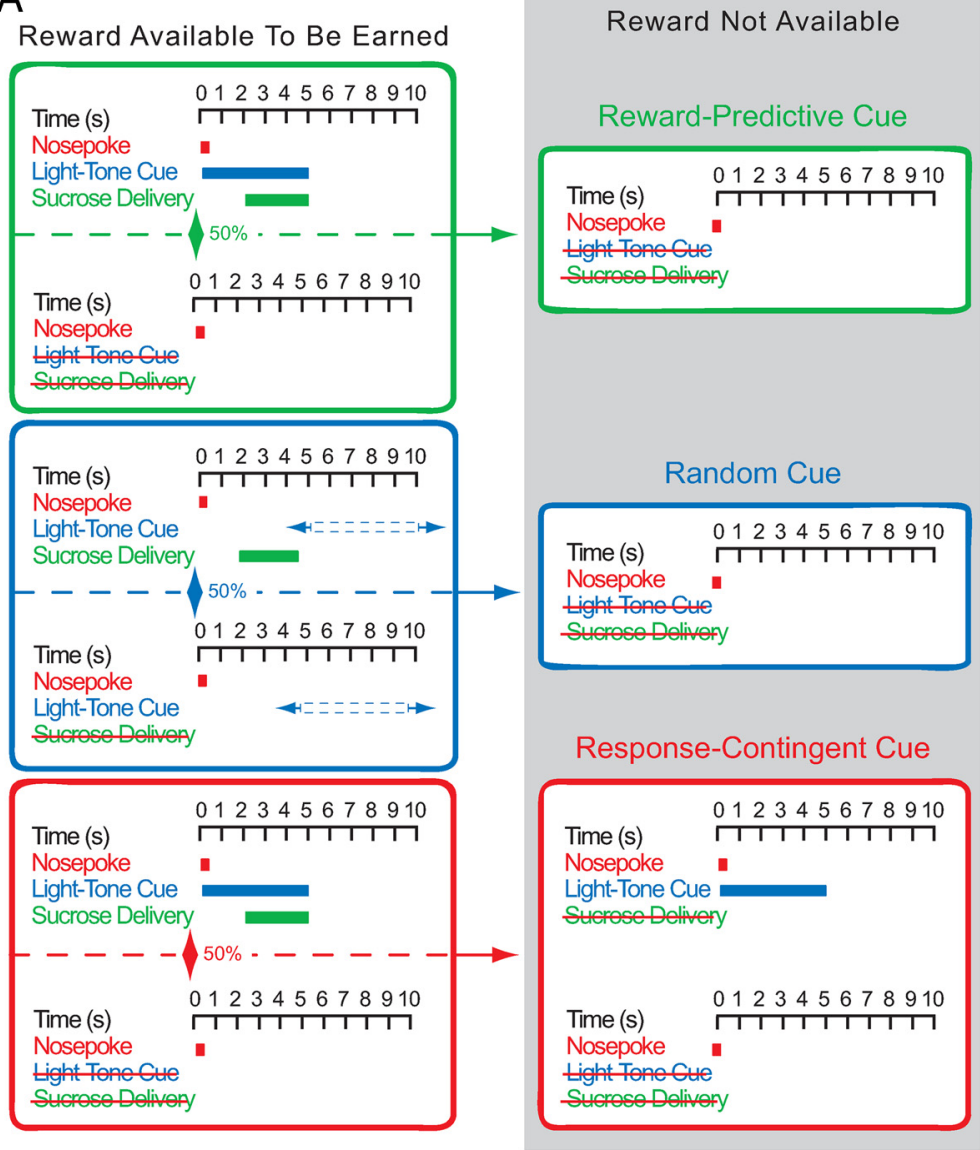

B

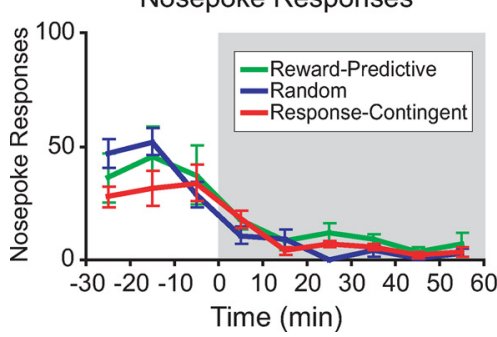

$\mathrm{C}$

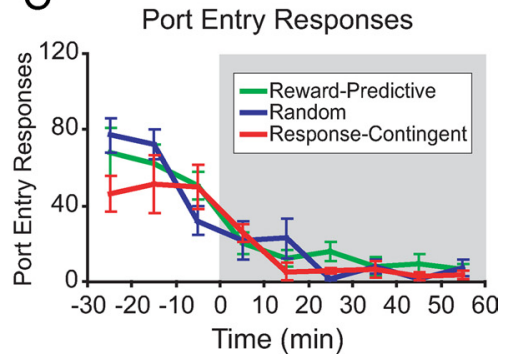

Figure 2. Diagram of behavioral procedures and behavioral responding. $\boldsymbol{A}$, Rats were trained for $5 \mathrm{~d}$ on one of three partial reinforcement procedures ("reward-predictive cue," "random cue," and "response-contingent cue") wherein $\sim 50 \%$ of operant responses at a nosepoke operandum were reinforced with subsequent sucrose delivery at an adjacent port. On the sixth day, an abbreviated training session was immediately followed by an unexpected within-session extinction procedure wherein operant responses were not reinforced and sucrose solution was not available. $\boldsymbol{B}, \boldsymbol{C}$, Mean nosepoke $(\boldsymbol{B})$ or port entry $(\boldsymbol{C})$ responses (in 10 min bins) are shown across the maintenance and extinction segments of the within-session extinction procedure for each treatment group ( $n=5$ rats each group); error bars indicate SEM. tion was normalized to the mean peak frequency during maintenance to obtain a measure we termed "response intensity."

Additionally, we examined the rate of extinction by comparing the nosepoke response rate during the last $10 \mathrm{~min}$ of extinction relative to the entire extinction session, a measure we termed "extinction resistance." We found a significant correlation $(r=$ $0.6327, p=0.0114$; Pearson's correlation test) between an individual rat's response intensity and extinction resistance (Fig. 3B).

\section{Neural encoding of port entry and sucrose}

Of 330 BLA neurons we recorded during this session, 194 (59\%) neurons exhibited a change in activity upon reward port entry. The response profiles of these neurons were heterogeneous both 


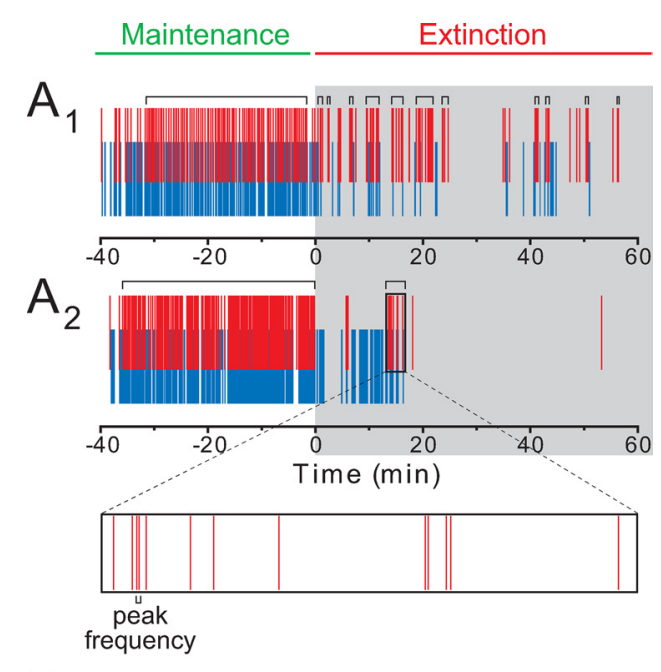

B

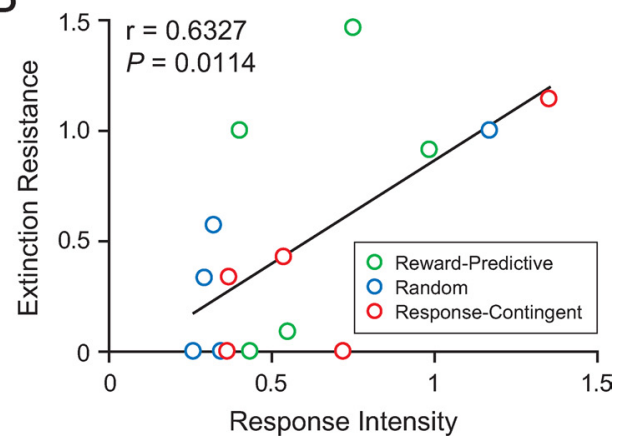

Figure 3. Changes in behavioral patterns that occur upon within-session extinction are variable. $A$, Behavioral rasters from two representative rats. $A_{1}, A$ behavioral raster from a rat that is more resistant to extinction than the rat in $\boldsymbol{A}_{2}$. Red ticks represent nosepoke responses, and blue ticks represent port entries. Time $=0$ signals the onset of the extinction session. Gray shading indicates extinction epochs during which sucrose reinforcement is unavailable. Horizontal brackets above rasters indicate bursts of nosepoke responses, as determined by burst analysis. Expanded box is an example depicting the peak frequency within the example burst. $\boldsymbol{B}$, Extinction resistance is significantly correlated with response intensity. Extinction resistance is calculated by dividing the rate of nosepoke responding during the last 10 min of the extinction epoch by the rate of nosepoke responding during the entire extinction epoch. Response intensity is defined as the mean peak frequency within a nosepoke burst during extinction normalized to the mean peak frequency during maintenance for each rat. Training procedure for each rat is indicated by color: green indicates training with the "reward-predictive cue" procedure, blue indicates training with the "random cue" procedure, and red indicates training with the "response-contingent cue" procedure; these colors will reflect the respective training procedures in all subsequent figures.

within and across groups and the characterization of these neuronal subpopulations is detailed in Table 1. One subpopulation of neurons showed phasic responses to port entries under any condition (Fig. 4A-D), regardless of whether sucrose was present or absent, or if the port entry occurred during maintenance or extinction, and was hence termed "all port entry" ( $n=31 ; 9 \%$ of all neurons recorded). While "all port entry"-responsive neurons may just encode the motoric output of entering the port, many other populations showed conditional specificity. The largest population of port-entry-responsive neurons were neurons that selectively responded to the presence of sucrose (sucrose port entry; $n=50 ; 15 \%$ ), hence termed "sucrose-only" neurons (Fig. $4 E-H)$. Conversely, another population of neurons termed "empty port" neurons, showed phasic responses only to port entries when sucrose was absent $(n=15 ; 5 \%)$, regardless of whether the port entry occurred during maintenance or extinction.

\section{A population of neurons develops a response to empty port entries only upon extinction}

A total of 79 of 330 neurons (24\%) developed a response to the empty port only during extinction. Within this population of neurons, two primary subpopulations can be identified by their responsiveness to port entries when sucrose is present. Importantly, our partial reinforcement schedule allowed us to compare neuronal responses to the same event, port entry when sucrose is absent (empty port entry), during either maintenance or extinction. A significant population of neurons termed "extinctiononly" neurons ( $n=47 ; 14 \%)$ showed no phasic change in activity upon port entries during maintenance, regardless of whether sucrose was present or absent, but developed a phasic response to empty port entries during extinction (Figs. 5, 6).

Forty-one of forty-seven "extinction-only" neurons exhibited an inhibition in phasic activity upon port entries during extinction. Ten of these forty-one neurons showed a tonic change in firing upon extinction, in addition to a phasic change in firing. Figure $5 \mathrm{~A}$ shows a population histogram of three neurons (out of 11 total simultaneously recorded neurons) that show a selective inhibition to empty port entries only during the within-session extinction procedure from a representative rat. Throughout the course of extinction, the latency between the nosepoke and the subsequent port entry increased as the animal extinguished reward-seeking behavior (values represent group mean seconds \pm SEM; early extinction $=6.132 \pm 1.194$ and late extinction $=76.026 \pm 18.986 ; p=0.002$ ). The boundary between early and late extinction is defined as the trial for which the latency between the nosepoke and the subsequent port entry was $>2$ SDs from the session mean. Furthermore, given a port entry response, the probability that the next behavioral response that the rat will perform is a nosepoke response, rather than another port entry response, significantly decreased in late extinction relative to early extinction (Fig. $5 B)\left(\chi^{2}=6.578 ; p=0.010\right)$. Of these 31 "extinction-only" neurons that showed phasic inhibitions, the relative proportion of neurons of this type per rat was inversely correlated with response intensity (Fig. 5C), suggesting that the more neurons recruited to this population, the less intensity of responding during extinction.

This correlation was not observed when the "extinction-only" neurons displaying phasic excitation to the empty port during extinction $(n=6)$ (Table 1$)$ were included, suggesting that this subpopulation of cells may be functionally distinct from "extinction-only" cells showing phasic inhibitions. The response of a representative neuron that developed a phasic increase in activity in response to empty port entries upon extinction onset is shown in a surface plot in Figure $6 \mathrm{~A}$. During early extinction, this neuron displays an increase in tonic firing rate as the phasic excitation develops. The transient increase in tonic firing rate returns to baseline upon late extinction, leaving a pronounced phasic excitation in response to empty port entry. Similar to the behavior of the representative rat shown in Figure $5 B$, this rat also shows a significant shift (decrease) in the probability of a nosepoke following a port entry response in late extinction (Fig. $6 B$ ) $\left(\chi^{2}=4.338 ; p=0.036\right)$.

\section{Response intensity and extinction resistance correspond to the proportion of reinforcement-omission-encoding neurons per rat}

The "extinction-only" neurons $(n=47)$, discussed above, respond selectively to the empty port entries occurring during extinction (Fig. 7). However, 32 of the 79 neurons that developed a response to the empty port only upon extinction onset also 
Table 1. Details of the heterogeneous port entry response profiles of all neurons recorded

\begin{tabular}{|c|c|c|c|c|c|c|c|c|c|c|c|}
\hline \multirow[b]{3}{*}{ Population } & \multicolumn{3}{|c|}{ Port entries during } & \multicolumn{2}{|c|}{ All rats pooled } & \multicolumn{2}{|c|}{ Rew. predictive } & \multicolumn{2}{|c|}{ Random } & \multicolumn{2}{|c|}{ Resp. contingent } \\
\hline & \multicolumn{2}{|c|}{ Maintenance } & \multirow{2}{*}{$\begin{array}{l}\text { Extinction } \\
\text { Empty }\end{array}$} & \multirow[b]{2}{*}{$n$} & \multirow{2}{*}{$\begin{array}{l}\% \text { of } \\
\text { total } \\
(n=330)\end{array}$} & \multirow[b]{2}{*}{$n$} & \multirow{2}{*}{$\begin{array}{l}\% \text { of } \\
\text { total } \\
(n=88)\end{array}$} & \multirow[b]{2}{*}{$n$} & \multirow{2}{*}{$\begin{array}{l}\% \text { of } \\
\text { total } \\
(n=93)\end{array}$} & \multirow[b]{2}{*}{$n$} & \multirow{2}{*}{$\begin{array}{l}\% \text { of } \\
\text { total } \\
(n=149)\end{array}$} \\
\hline & Sucrose & Empty & & & & & & & & & \\
\hline \multirow[t]{3}{*}{ Reinforcement omission ( $n=32 / 330 ; 10 \%)$} & $\downarrow$ & - & $\downarrow$ & $22 / 32$ & $7 \%$ & $5 / 88$ & $6 \%$ & $6 / 93$ & $6 \%$ & $11 / 149$ & $7 \%$ \\
\hline & $\uparrow$ & - & $\downarrow$ & $7 / 32$ & $2 \%$ & $3 / 88$ & $3 \%$ & $2 / 93$ & $2 \%$ & $2 / 149$ & $1 \%$ \\
\hline & $\downarrow$ & - & $\uparrow$ & $3 / 32$ & $1 \%$ & $1 / 88$ & $1 \%$ & $0 / 93$ & $0 \%$ & $2 / 149$ & $1 \%$ \\
\hline \multirow[t]{2}{*}{ Extinction only ( $n=47 / 330 ; 14 \%)$} & - & - & $\downarrow$ & $41 / 47$ & $9 \%$ & $12 / 88$ & $14 \%$ & $13 / 93$ & $14 \%$ & $16 / 149$ & $11 \%$ \\
\hline & - & - & $\uparrow$ & $6 / 47$ & $2 \%$ & $3 / 88$ & $3 \%$ & $3 / 93$ & $3 \%$ & $0 / 149$ & $0 \%$ \\
\hline \multirow[t]{2}{*}{ Maint. only $(n=4 / 330 ; 1 \%)$} & $\uparrow$ & $\uparrow$ & - & $3 / 4$ & $1 \%$ & $0 / 88$ & $0 \%$ & $3 / 93$ & $3 \%$ & $0 / 149$ & $0 \%$ \\
\hline & $\downarrow$ & $\downarrow$ & - & $1 / 4$ & $0.30 \%$ & $0 / 88$ & $0 \%$ & $0 / 93$ & $0 \%$ & $1 / 149$ & $0.70 \%$ \\
\hline \multirow[t]{2}{*}{ Empty in Maint. $(n=17 / 330 ; 5 \%)$} & - & $\downarrow$ & - & $15 / 17$ & $4.50 \%$ & $5 / 88$ & $6 \%$ & $2 / 93$ & $2 \%$ & $8 / 149$ & $5 \%$ \\
\hline & - & $\uparrow$ & - & $2 / 17$ & $0.60 \%$ & $1 / 88$ & $1 \%$ & $0 / 93$ & $0 \%$ & $1 / 149$ & $0.70 \%$ \\
\hline \multirow[t]{4}{*}{ Empty port $(n=15 / 330 ; 5 \%)$} & - & $\downarrow$ & $\downarrow$ & $10 / 15$ & $3 \%$ & $2 / 88$ & $2 \%$ & $2 / 93$ & $2 \%$ & $6 / 149$ & $4 \%$ \\
\hline & - & $\uparrow$ & $\uparrow$ & $3 / 15$ & $1 \%$ & $1 / 88$ & $1 \%$ & $1 / 93$ & $1 \%$ & $1 / 149$ & $0.70 \%$ \\
\hline & - & $\uparrow$ & $\downarrow$ & $1 / 15$ & $0.30 \%$ & $0 / 88$ & $0 \%$ & $0 / 93$ & $0 \%$ & $1 / 149$ & $0.70 \%$ \\
\hline & - & $\downarrow$ & $\uparrow$ & $1 / 15$ & $0.30 \%$ & $0 / 88$ & $0 \%$ & $0 / 93$ & $0 \%$ & $1 / 149$ & $0.70 \%$ \\
\hline \multirow[t]{2}{*}{ Sucrose only ( $n=50 / 330 ; 15 \%)$} & $\downarrow$ & - & - & $37 / 50$ & $11 \%$ & $12 / 88$ & $14 \%$ & $11 / 93$ & $12 \%$ & $14 / 149$ & $9 \%$ \\
\hline & $\uparrow$ & - & - & $13 / 50$ & $4 \%$ & $6 / 88$ & $7 \%$ & $7 / 93$ & $8 \%$ & $0 / 149$ & $0 \%$ \\
\hline \multirow[t]{5}{*}{ All port entries ( $n=31 / 330 ; 9 \%)$} & $\downarrow$ & $\downarrow$ & $\downarrow$ & $23 / 31$ & $7 \%$ & $5 / 88$ & $6 \%$ & $5 / 93$ & $5 \%$ & $13 / 149$ & $9 \%$ \\
\hline & $\uparrow$ & $\uparrow$ & $\uparrow$ & $5 / 31$ & $1.60 \%$ & $3 / 88$ & $3 \%$ & $1 / 93$ & $1 \%$ & $1 / 149$ & $0.70 \%$ \\
\hline & $\downarrow$ & $\downarrow$ & $\uparrow$ & $1 / 31$ & $0.30 \%$ & $0 / 88$ & $0 \%$ & $0 / 93$ & $0 \%$ & $1 / 149$ & $0.70 \%$ \\
\hline & $\downarrow$ & $\uparrow$ & $\downarrow$ & $1 / 31$ & $0.30 \%$ & $0 / 88$ & $0 \%$ & $1 / 93$ & $1 \%$ & $0 / 149$ & $0 \%$ \\
\hline & $\uparrow$ & $\downarrow$ & $\downarrow$ & $1 / 31$ & $0.30 \%$ & $1 / 88$ & $1 \%$ & $0 / 93$ & $0 \%$ & $0 / 149$ & $0 \%$ \\
\hline No response $(n=134 / 330 ; 41 \%)$ & - & - & - & $134 / 330$ & $41 \%$ & $28 / 88$ & $32 \%$ & $36 / 93$ & $39 \%$ & $70 / 149$ & $47 \%$ \\
\hline
\end{tabular}

Here, each population and subpopulation is detailed with neuron counts and changes in phasic activity in each port entry scenario. Upward arrows indicate an increase in firing during the response window ( 0 - 500 ms following port entry; $p<0.01)$, downward arrows indicate a decrease in phasic activity, and the flat line indicates no change. Categorization by response profile in terms of cell number and proportions are shown for all rats pooled, the reward-predictive cue group, the random cue group, and the response contingent cue group in separate columns. Maint., Maintenance; Rew., reward; Resp, response.

showed a phasic response to port entries when sucrose was present ( $10 \%$ of all 330 neurons recorded) (Fig. $8 A-D)$. Since this population of neurons was selectively responsive to the presence of sucrose during maintenance and developed a phasic response to the empty port only upon extinction, we termed them "reinforcement-omission" neurons, as these neurons remapped their response profiles upon unexpected reinforcement omission during our within-session extinction procedure. Twenty-two of these thirty-two neurons were phasically inhibited to both port entries when sucrose was present and port entries during extinction (Fig. $8 A, B$ ). The other 10 cells of these 32 units showed opposite phasic changes: 7 showed a phasic excitation upon port entries when sucrose was present, no phasic response upon empty port entries during maintenance, and then a phasic decrease in activity upon empty port entries during extinction (Fig. $8 C, D$, Table 1 ). The other 3 units in this population were inhibited upon sucrose port entries, and excited upon empty port entries during extinction (Table 1).

Although the majority of rats in our task did not show a dramatic increase in response intensity during extinction relative to maintenance (Fig. 3C), perhaps due to the nature of training under a partial reinforcement schedule (see Discussion), the behavioral variability during extinction allowed us to observe the relationship between behavioral measures and the proportion of neurons with a given response profile. We found that the proportion of neurons in the "reinforcement-omission" population out of the total number of neurons per rat was significantly correlated with each rat's response intensity (Fig. $8 E)(r=0.7476, p=0.0033)$ and extinction resistance (Fig. $8 F)(r=0.5671 ; p=0.0433)$. These correlations were nonrandom, as no other population of neurons was significantly correlated to either of these measures (Table 2). Furthermore, none of the neuronal populations we identified were correlated with total numbers of nonreinforced responses or with extinction slope for responses at either the nosepoke operandum or the sucrose delivery port (Table 2 ).

\section{Discussion}

Here, we report that BLA neurons encode the changes in outcome availability that occur during extinction by remapping their phasic response profiles upon extinction of reward-seeking behavior. Specifically, amygdala neurons responded to the absence of reward delivery during extinction. Because we found that the activity of a population of these neurons, termed "reinforcementomission" neurons, was positively correlated with response intensity (Fig. 8E) and extinction resistance (Fig. $8 F$ ), these neurons may contribute to the maintenance of behavioral responding during extinction.

\section{Neural correlates of extinction in the BLA}

Because we used a partial reinforcement schedule, we were able to compare neuronal responses to the empty port during extinction to port entries during maintenance in the presence or absence of sucrose. Of 330 neurons, 79 developed a phasic response to empty port entries during extinction (24\%) that had no response to the empty port during maintenance. Of these, the largest population (14\%; "extinction-only") developed a response to the reward port during extinction that was not present during maintenance in the presence or absence of sucrose.

The second major population of neurons $(10 \%)$ responded to the presence of sucrose during maintenance and developed a 

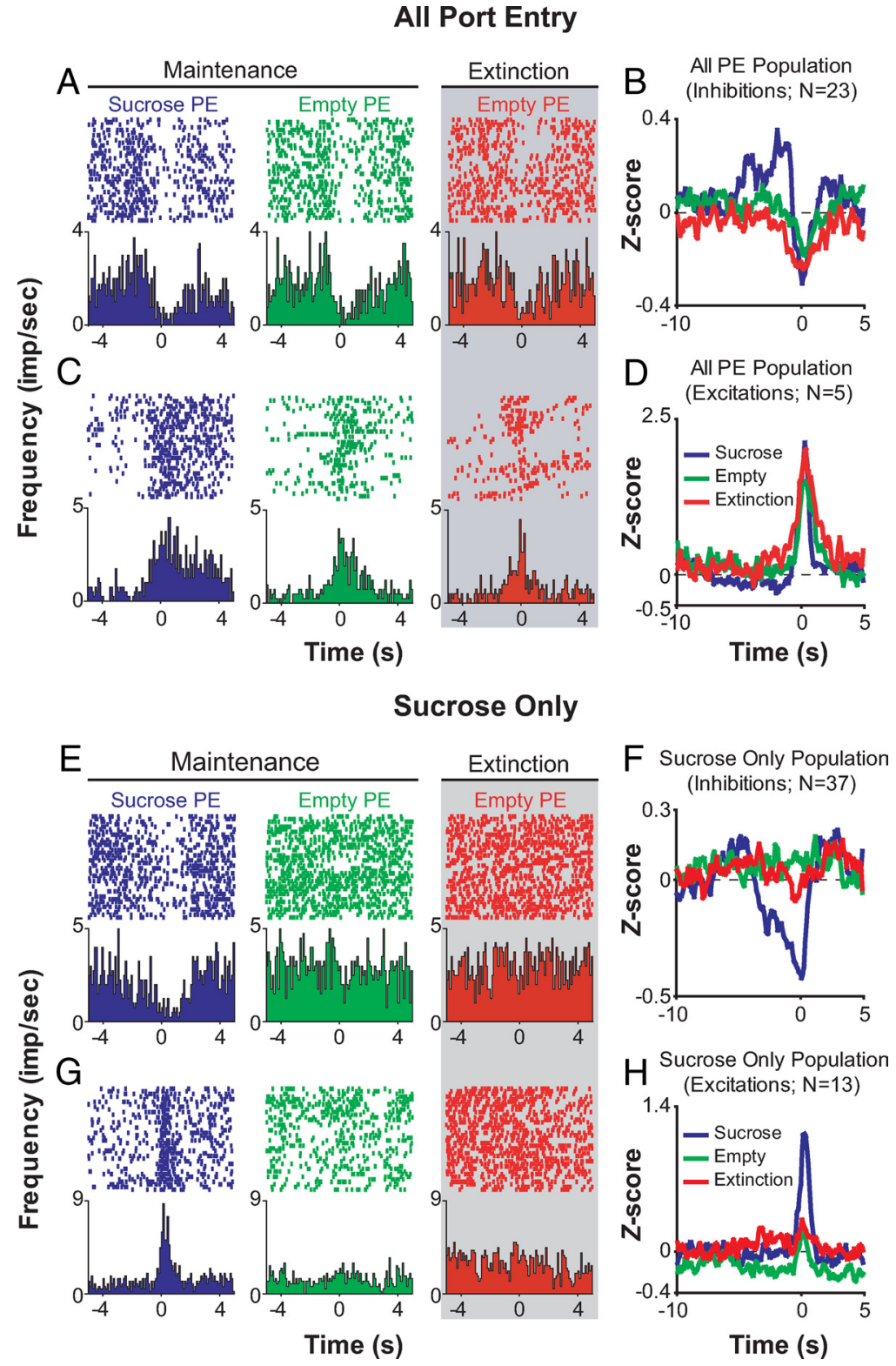

Figure 4. One population of BLA neurons responds to all port entries regardless of condition, while another population of neurons responds to port entries only when sucrose is present. $A-D, 0 f 31$ neurons that responded to all three $P E$ conditions, 28 neurons responded to all port entry conditions with similar phasic responses. Perievent raster histograms show neural activity when the rat enters the sucrose delivery port under three conditions: (1) during maintenance when the port is filled with sucrose, (2) during maintenance when the port is empty, and (3) during extinction, when the port is always empty. Gray shading indicates epochs when sucrose is unavailable. For all perievent raster histograms, the port entry beam break occurs at time $=0 . \boldsymbol{A}$, Example perievent raster histograms from a neuron that is inhibited upon all port entries in maintenance and extinction. $\boldsymbol{B}$, Population perievent histograms of mean normalized firing rate from the 23 neurons that displayed phasic inhibitions upon all port entries. C, Example perievent raster histograms from a neuron that is excited upon all port entries during maintenance and extinction. $\boldsymbol{D}$, Population perievent histograms from the five neurons that are excited by all port entries in maintenance and extinction. $\boldsymbol{E}$, Example perievent raster histograms from a neuron that is inhibited only during port entries when sucrose is present. $\boldsymbol{F}$, Population perievent histograms from the 37 neurons that displayed phasic inhibitions upon port entries in the presence of sucrose. G, Example perievent raster histograms from a neuron that showed a phasic excitation upon port entry in the presence of sucrose. $\boldsymbol{H}$, Population perievent histograms from the 13 neurons that displayed phasic excitations upon port entries when sucrose was present.

response to the empty port during extinction. As these neurons were initially sensitive to reinforcement, and then remapped their response profiles upon unexpected reinforcement omission, we termed them "reinforcement-omission" neurons. This population was primarily neurons with inhibitions to sucrose and to the empty port during extinction; however, one-third of this popu- lation displayed opposite changes in firing to sucrose and to the empty port during extinction. Together, the relative proportion of these neurons recorded within each rat was predictive of both response intensity and extinction resistance. Thus, subsets of BLA neurons are highly responsive to the change in outcome availability in the context of extinction.

Neurons responsive to all port entries (Fig. 4) may encode recognition of the port as a motivationally significant cue. Similarly, neurons responsive to port entries when sucrose was present (Fig. 4) may encode reinforcement in general, or the specific value or sensory attributes of the outcome (Schoenbaum et al., 1998; Belova et al., 2007). In contrast, neurons that responded to the empty port only during extinction must specifically encode the change in reward availability. We demonstrate that the unexpected absence of reward during extinction is encoded differently than the expected absence of reward during responding in maintenance.

Interestingly, 66 of the 79 neurons (84\%) that developed phasic responses to the empty port upon extinction were phasic inhibitions. Eighty-five to ninety-five percent of BLA neurons are glutamatergic projection neurons with the remainder comprised of GABA-ergic neurons, either interneurons distributed within the nuclei or part of the intercalated cell masses around the BLA (McDonald, 1984; Washburn and Moises, 1992; McDonald and Augustine, 1993; Marowsky et al., 2005; Ehrlich et al., 2009). As the majority of neurons we recorded were likely glutamatergic projection neurons receiving inhibitory input from local interneurons and intercalated cells, our findings are consistent with the notion that local inhibitory circuits in the amygdala play a critical role in extinction (Ehrlich et al., 2009).

Our results are consistent with a growing body of literature implicating the amygdala in fear extinction (Quirk and Mueller, 2008; Ehrlich et al., 2009). Inactivation of the BLA with muscimol blocks acquisition of fear extinction (Sotres-Bayon et al., 2007; Herry et al., 2008). In addition, a distinct population of neurons in the BLA develops a response to a shock-conditioned cue after behavioral extinction (Herry et al., 2008). Our studies extend these neural recording findings by identifying changes in the neural response to the reinforcer/ outcome, which is relatively more difficult to measure in fear conditioning studies, and extend the study of neural activity during extinction into instrumentally conditioned responses rather than Pavlovian conditioned responses. Our findings support a more gen- 


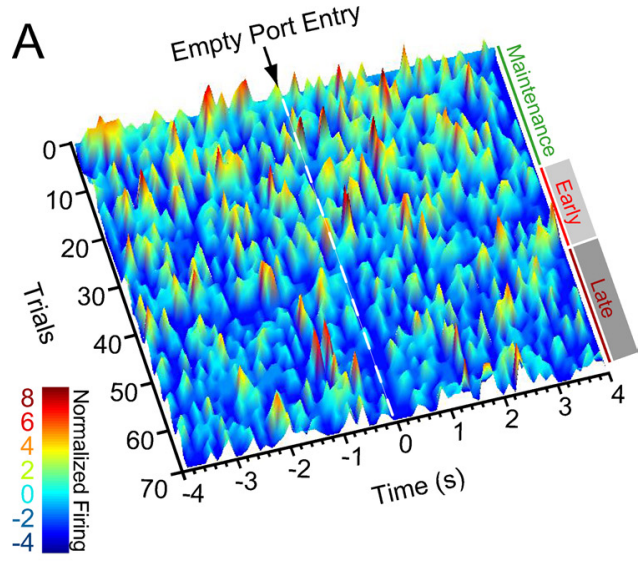

$\mathrm{B}$

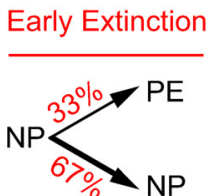

Late Extinction

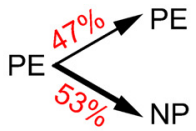

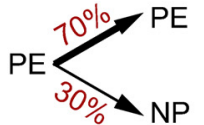

\section{C}

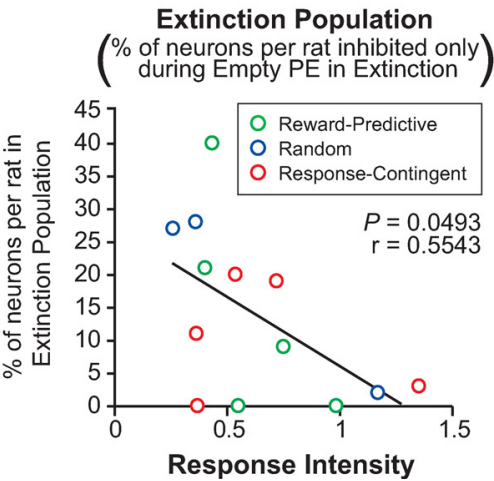

Figure 5. A subpopulation of neurons developed a phasic inhibition to the empty port during acquisition of extinction. Early extinction began at the onset of the extinction epoch, when sucrose was unavailable. Late extinction is defined as beginning on the first trial when the latency between the nosepoke response and the subsequent port entry is 2 SDs greater than the session mean. $\boldsymbol{A}$, Temporal dynamics of three neurons that developed a phasic inhibition to the empty port from a representative rat. Surface plot of normalized firing rate was calculated using $150 \mathrm{~ms}$ bins, and was smoothed for \pm 1 trial. B. Microanalysis of behavior during the extinction epoch. Given that a nosepoke response occurred, the probability of occurrence of the next behavioral response did not change from early to late extinction. Given that a port entry occurred, the probability that the rat would perform another port entry before performing a nosepoke increased during late extinction $(p<0.05)$. C, The proportion of neurons that developed a phasic inhibition upon empty port entry only during extinction was inversely correlated with response intensity.

eral role of the BLA in processing extinction learning, independent of reinforcer valence.

Our data also complement findings implicating the BLA in the extinction of appetitively conditioned responses; specifically, McLaughlin and Floresco (2007) reported that pharmacological inactivation of the BLA impairs extinction of responding for food reward, in agreement with the idea that neural activity within the BLA contributes to changes in responding produced by extinction. Finally, our findings are congruent with lesion studies that
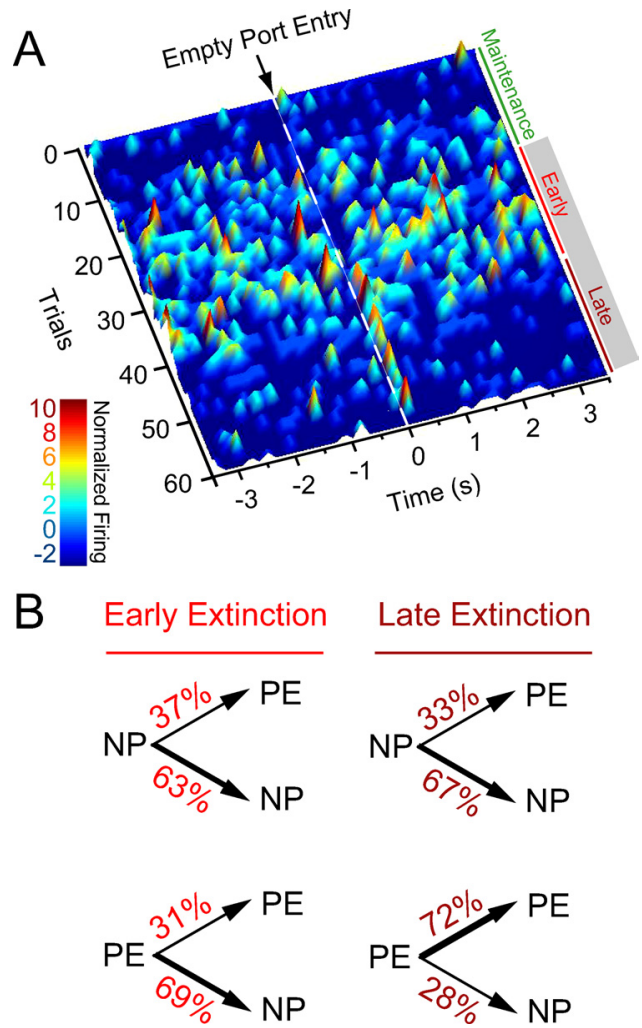

Late Extinction
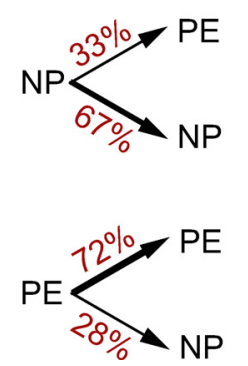

Figure 6. A subpopulation of neurons developed a phasic excitation to the empty port during acquisition of extinction. $\boldsymbol{A}$, Temporal dynamics of a BLA neuron that developed a phasic excitation to the empty port during extinction from another representative rat. Surface plot of normalized firing rate was calculated using $150 \mathrm{~ms}$ bins, and was smoothed for \pm 1 trial. $\boldsymbol{B}$, This rat also shows an increase in the probability of performing another port entry following a port entry during late extinction, relative to early extinction $(p<0.05)$.

demonstrate a role for the BLA in representing specific outcomes, and, critically, for the ability of changes in the value of an outcome to impact responding (Balleine et al., 2003; Corbit and Balleine, 2005; McLaughlin and Floresco, 2007; Ehrlich et al., 2009).

Role of BLA neuronal correlates in reward-seeking extinction In extinction, an animal learns that the previously conditioned response is no longer reinforced (Pavlov, 1927), creating a distinct action-no outcome association. The neural mechanisms of extinction, particularly the extinction of reward seeking, are poorly understood. Extinction has been hypothesized to be an "unlearning" process due to a violation of the learned association (Rescorla and Wagner, 1972), and this hypothesis is supported by evidence that extinction reverses fear conditioning-induced potentiation at thalamo-amygdala synapses (Kim et al., 2007). However, a competing hypothesis suggests that extinction is mediated by formation of new associations that inhibit, rather than erase, expression of the original learned association (Pavlov, 1927; Bouton and King, 1983; Rescorla, 2001; Myers and Davis, 2002; Quirk et al., 2006; Ehrlich et al., 2009).

If extinction were new learning, then one would expect to observe the appearance of new neural correlates during extinction that signal the change in reinforcer contingencies. In the present study of sucrose-reinforced instrumental responding, the development of an inhibitory action-no outcome association should require a neural signal corresponding to the absence of 


\section{Extinction Only}
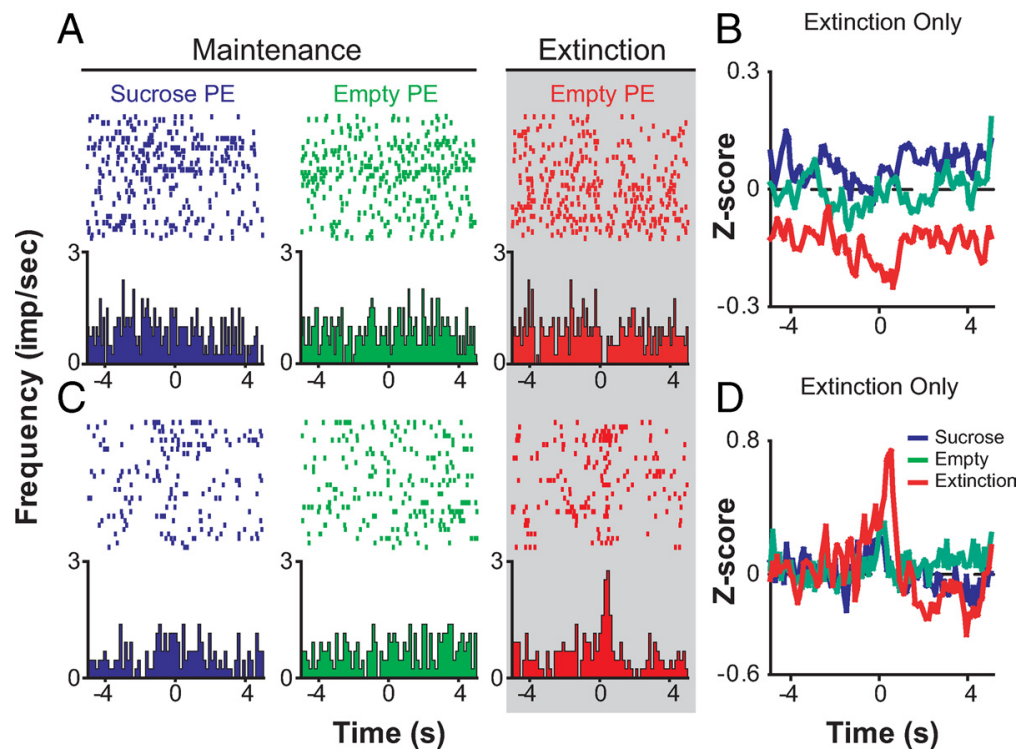

Figure 7. A population of BLA neurons selectively responded to empty port entries during the extinction epoch only. Of the 47 neurons in the "extinction-only" population that selectively responded to extinction PEs, 41 responded with phasic inhibitions. $\boldsymbol{A}$, Example perievent raster histograms from a neuron that developed a phasic inhibition to empty port entries only during the extinction epoch. $\boldsymbol{B}$, Population histogram of normalized activity for the 31 neurons that are inhibited only during extinction: the 10 neurons that displayed tonic changes in firing rate were not included in this population histogram. C, Example perievent raster histograms from a neuron that developed a phasic excitation to empty port entries only during the extinction epoch. D, Population histograms for the six neurons that are excited by port entries only during extinction.

reward. The "extinction-only" neurons may provide, at least in part, this signal of reward omission. When considering only the 41 of 47 neurons in the "extinction-only" population that showed phasic inhibitions to port entries only during extinction, the proportion of these neurons per rat showed a strong trend toward an inverse correlation with response intensity $(r=-0.5543, p=$ 0.0493 ) (Fig. 5C). While speculative, this idea is consistent with findings that inactivation of the BLA impairs extinction acquisition (Sotres-Bayon et al., 2007; Herry et al., 2008), including extinction of operant responding for food (McLaughlin and Floresco, 2007).

The intensity of responding during extinction varied considerably among our subjects (Fig. 2). Competition between newly forming inhibitory associations and the original excitatory association may contribute to the behavioral variability during a within-session extinction procedure in which the animal has recently experienced both contingencies, and may explain the sporadic, high-intensity bouts of responding we observed during extinction. We used this to our advantage to probe neural mechanisms underlying responding during extinction. We speculated that the intensity of responding was related to the continued expectation of reward. A subpopulation of "reinforcementomission" neurons (22 of 32 cells), showed phasic inhibitions upon both sucrose port entries during maintenance and empty port entries during extinction, but not empty port entries during maintenance. During extinction, the continued phasic responsiveness of these neurons related to the expected but omitted reward may contribute to maintained motivation of the animal to continue responding for rewards despite a change in responseoutcome contingency. We hypothesize that this neuronal subpopulation encodes the memory or expectation of the sucrose reward during extinction. The remaining neurons (10 of 32) in the "reinforcement-omission" population, which showed oppo- site phasic changes in response to the sucrose port entries and extinction port entries, may mediate the distinction between the expected reward and reward omission.

We hypothesized that, together, these neuronal subpopulations comprising the "reinforcement-omission" population support the continued responding for reward during extinction and detect the value difference between expected and actual outcomes, therefore contributing to enhanced instrumental response intensity and extinction resistance. Indeed, we found that the proportion of neurons in the "reinforcementomission" per rat was strongly correlated with each rat's response intensity (Fig. $8 E$ ) and extinction resistance (Fig. $8 F$ ).

We did not observe significant correlations between reinforcement-omission and extinction-only neuronal populations and measures of total nonreinforced responding during extinction or with the slope of the extinction curve (Table 2). This may be due to the highly variable and sporadic response patterns observed upon extinction onset in our within-session extinction procedure, and suggests to us that the examination of neural correlates of extinction was facilitated by normalizing the behavior of each subject to that subject's baseline responding, as in the response intensity measure.

\section{BLA involvement in expression of "the frustration effect"}

The amygdala has been implicated in mediating the behavioral phenomenon, termed "the reinforcement-omission effect" or "frustration effect," that occurs when an animal trained to respond for a positive reinforcer unexpectedly finds that the reinforcer is omitted following the operant response previously associated with reinforcer procurement (Amsel and Roussel, 1952; Henke, 1973; Henke and Maxwell, 1973; Dudley and Papini, 1997; Abler et al., 2005; Ernst et al., 2005). Hull (1952) first described this behavioral phenomenon, stating that "the abrupt cessation of a customary reinforcement" results in an initial, transient increase in operant responding. Although using a partial reinforcement procedure while recording neural activity in vivo allows us to control for specific conditions under different contingencies, it also results in greater variability in the expression of "the reinforcement-omission effect" during extinction (Amsel, 1958). BLA lesions attenuate the expression of "the frustration effect” (Henke, 1973; Henke and Maxwell, 1973), consistent with our finding that the proportion of neurons encoding the omitted sucrose reinforcer predicts response intensity during extinction (Fig. 8). It is an intriguing possibility that the "reinforcementomission" neuronal responses we have identified here contribute to expression of "the frustration effect" during extinction.

\section{Conclusion}

In conclusion, we report that upon unexpected reward omission during a within-session extinction procedure, BLA neurons remap their phasic response profiles with the acquisition of extinction. These findings encourage future experimentation to elucidate the synaptic and circuit mechanisms in the BLA and 


\section{Reinforcement Omission}
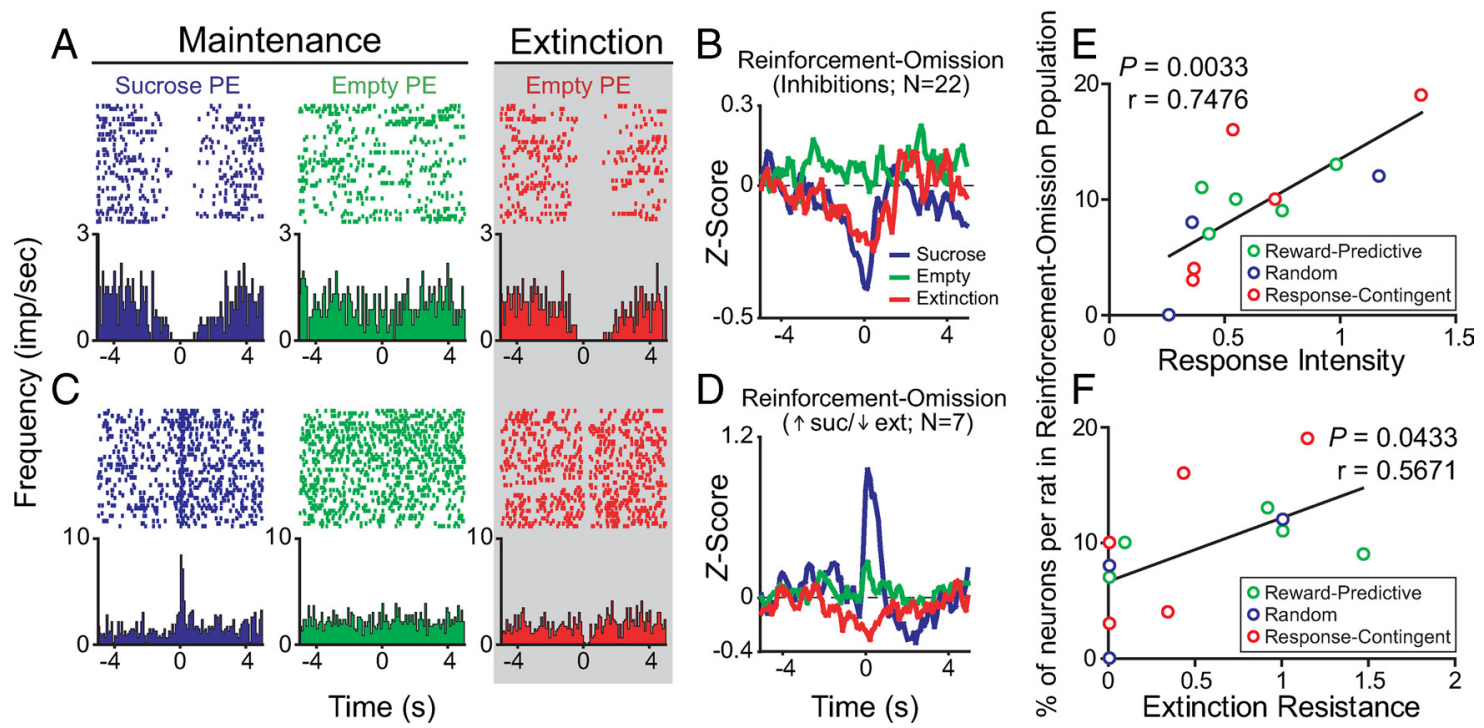

Figure 8. A subpopulation of BLA neurons that encoded port entries in the presence of the sucrose reinforcer developed a phasic response to the empty port only during the extinction epoch and predicts response intensity and extinction resistance. $A$, A representative BLA neuron that was inhibited by port entries when sucrose is present, did not respond to port entries when sucrose was absent during maintenance, but developed a phasic inhibition upon port entries when sucrose was absent during extinction only. $\boldsymbol{B}$, Population histograms of normalized activity for each port entry condition including the 22 neurons that displayed a similar response profile to that of the representative neuron in $A$. C, A representative BLA neuron that was excited by port entries when sucrose is present, did not respond upon port entries when sucrose was absent during maintenance, but was inhibited by port entries when sucrose was absent during extinction. $\boldsymbol{D}$, Population histograms showing normalized activity in each port entry condition for neurons with response profiles such as the neurons shown in C.E, The proportion of neurons in the "reinforcement-omission" population recorded per rat was significantly correlated with each rat's response intensity $(\boldsymbol{E})$ and extinction resistance $(\boldsymbol{F})$.

Table 2. Linear regression scores and $p$ values for correlations between all neuronal populations and behavioral measures

\begin{tabular}{|c|c|c|c|c|c|c|}
\hline \multirow[b]{2}{*}{ Population } & \multirow[b]{2}{*}{ Extinction resistance } & \multirow[b]{2}{*}{ Response intensity } & \multicolumn{2}{|c|}{ Total nonreinforced responses } & \multicolumn{2}{|c|}{ Extinction slope } \\
\hline & & & Nosepoke & Port entry & Nosepoke & Port entry \\
\hline \multicolumn{7}{|c|}{ Reinforcement omission ( $n=32 / 330 ; 10 \%)$} \\
\hline$r^{2}$ & 0.3216 & 0.5590 & 0.0206 & 0.0148 & 0.0430 & 0.0224 \\
\hline$p$ & 0.0433 & 0.0033 & 0.6398 & 0.6919 & 0.4964 & 0.6253 \\
\hline \multicolumn{7}{|c|}{ Extinction only ( $n=47 / 330 ; 14 \%)$} \\
\hline$r^{2}$ & 0.1764 & 0.2521 & 0.0660 & 0.0729 & 0.0118 & 0.1127 \\
\hline$p$ & 0.1530 & 0.0084 & 0.3967 & 0.3721 & 0.7242 & 0.2622 \\
\hline Maint. only $(n=4 / 330 ; 1 \%)$ & $N / A$ & $\mathrm{~N} / \mathrm{A}$ & $\mathrm{N} / \mathrm{A}$ & $N / A$ & $N / A$ & $\mathrm{~N} / \mathrm{A}$ \\
\hline \multicolumn{7}{|c|}{ Empty in Maint. $(n=17 / 330 ; 5 \%)$} \\
\hline$r^{2}$ & 0.07386 & 0.1130 & 0.0630 & 0.0573 & 0.0214 & 0.0239 \\
\hline$p$ & 0.3691 & 0.2614 & 0.4080 & 0.4306 & 0.6336 & 0.6143 \\
\hline \multicolumn{7}{|l|}{ Empty port $(n=15 / 330 ; 5 \%)$} \\
\hline$r^{2}$ & 0.0299 & 0.06619 & 0.0800 & 0.0032 & 0.0243 & 0.0738 \\
\hline$p$ & 0.5724 & 0.3916 & 0.3491 & 0.8536 & 0.6113 & 0.3639 \\
\hline \multicolumn{7}{|l|}{ Sucrose only $(n=50 / 330 ; 15 \%)$} \\
\hline$r^{2}$ & 0.07117 & 0.07795 & 0.0115 & 0.0388 & 0.0061 & 0.2316 \\
\hline$p$ & 0.3783 & 0.3556 & 0.7279 & 0.5188 & 0.8005 & 0.0959 \\
\hline \multicolumn{7}{|l|}{ All port entries $(n=31 / 330 ; 9 \%)$} \\
\hline$r^{2}$ & 0.00814 & 0.0005 & 0.5658 & 0.4435 & 0.3434 & 0.2666 \\
\hline$p$ & 0.7694 & 0.9419 & 0.0030 & 0.0130 & 0.0353 & 0.0708 \\
\hline \multicolumn{7}{|l|}{ No response $(n=134 / 330 ; 41 \%)$} \\
\hline$r^{2}$ & 0.0686 & 0.0459 & 0.0924 & 0.1912 & 0.0535 & 0.2114 \\
\hline$p$ & 0.3874 & 0.4823 & 0.3125 & 0.1351 & 0.4473 & 0.1140 \\
\hline
\end{tabular}

other neural substrates such as the prefrontal (Quirk et al., 2000, 2006; Rosenkranz et al., 2003; Peters et al., 2008) and orbitofrontal (Schoenbaum et al., 1998; Tremblay and Schultz, 2000; Schoenbaum and Roesch, 2005) cortices that may mediate the responses to the absence of reward during extinction.

\section{References}

Abler B, Walter H, Erk S (2005) Neural correlates of frustration. Neuroreport 16:669-672.
Amsel A (1958) The role of frustrative nonreward in noncontinuous reward situations. Psychol Bull 55:102-119.

Amsel A, Roussel J (1952) Motivational properties of frustration. I. Effect on a running response of the addition of frustration to the motivational complex. J Exp Psychol 43:363-366.

Balleine BW, Killcross AS, Dickinson A (2003) The effect of lesions of the basolateral amygdala on instrumental conditioning. J Neurosci 23:666-675.

Baxter MG, Murray EA (2002) The amygdala and reward. Nat Rev Neurosci 3:563-573. 
Belova MA, Paton JJ, Morrison SE, Salzman CD (2007) Expectation modulates neural responses to pleasant and aversive stimuli in primate amygdala. Neuron 55:970-984.

Bouton ME, King DA (1983) Contextual control of the extinction of conditioned fear: tests for the associative value of the context. J Exp Psychol Anim Behav Process 9:248-265.

Cador M, Robbins TW, Everitt BJ (1989) Involvement of the amygdala in stimulus-reward associations: interaction with the ventral striatum. Neuroscience 30:77-86.

Carelli RM, Williams JG, Hollander JA (2003) Basolateral amygdala neurons encode cocaine self-administration and cocaine-associated cues. J Neurosci 23:8204-8211.

Corbit LH, Balleine BW (2005) Double dissociation of basolateral and central amygdala lesions on the general and outcome-specific forms of pavlovian-instrumental transfer. J Neurosci 25:962-970.

Dudley RT, Papini MR (1997) Amsel's frustration effect: a pavlovian replication with control for frequency and distribution of rewards. Physiol Behav 61:627-629.

Ehrlich I, Humeau Y, Grenier F, Ciocchi S, Herry C, Lüthi A (2009) Amygdala inhibitory circuits and the control of fear memory. Neuron 62:757-771.

Ernst M, Nelson EE, Jazbec S, McClure EB, Monk CS, Leibenluft E, Blair J, Pine DS (2005) Amygdala and nucleus accumbens in responses to receipt and omission of gains in adults and adolescents. Neuroimage 25:1279-1291.

Falls WA, Miserendino MJ, Davis M (1992) Extinction of fear-potentiated startle: blockade by infusion of an NMDA antagonist into the amygdala. J Neurosci 12:854-863.

Henke PG (1973) Effects of reinforcement omission on rats with lesions in the amygdala. J Comp Physiol Psychol 84:187-193.

Henke PG, Maxwell D (1973) Lesions in the amygdala and the frustration effect. Physiol Behav 10:647-650.

Herry C, Mons N (2004) Resistance to extinction is associated with impaired immediate early gene induction in medial prefrontal cortex and amygdala. Eur J Neurosci 20:781-790.

Herry C, Ciocchi S, Senn V, Demmou L, Müller C, Lüthi A (2008) Switching on and off fear by distinct neuronal circuits. Nature 454:600-606.

Hull CL (1952) A behavior system: an introduction to behavior theory concerning the individual organism. New Haven, CT: Yale UP.

Janak PH, Redfern JE, Samson HH (1998) The reinforcing effects of ethanol are altered by the endogenous neurosteroid, allopregnanolone. Alcohol Clin Exp Res 22:1106-1112.

Kim J, Lee S, Park K, Hong I, Song B, Son G, Park H, Kim WR, Park E, Choe HK, Kim H, Lee C, Sun W, Kim K, Shin KS, Choi S (2007) Amygdala depotentiation and fear extinction. Proc Natl Acad Sci U S A 104: 20955-20960.

Likhtik E, Popa D, Apergis-Schoute J, Fidacaro GA, Paré D (2008) Amygdala intercalated neurons are required for expression of fear extinction. Nature 454:642-645.

Lin CH, Yeh SH, Lu HY, Gean PW (2003) The similarities and diversities of signal pathways leading to consolidation of conditioning and consolidation of extinction of fear memory. J Neurosci 23:8310-8317.

Lu KT, Walker DL, Davis M (2001) Mitogen-activated protein kinase cascade in the basolateral nucleus of amygdala is involved in extinction of fear-potentiated startle. J Neurosci 21:RC162(1-5).

Marowsky A, Yanagawa Y, Obata K, Vogt KE (2005) A specialized subclass of interneurons mediates dopaminergic facilitation of amygdala function. Neuron 48:1025-1037.

McDonald AJ (1984) Neuronal organization of the lateral and basolateral amygdaloid nuclei in the rat. J Comp Neurol 222:589-606.

McDonald AJ, Augustine JR (1993) Localization of GABA-like immunoreactivity in the monkey amygdala. Neuroscience 52:281-294.
McLaughlin J, See RE (2003) Selective inactivation of the dorsomedial prefrontal cortex and the basolateral amygdala attenuates conditioned-cued reinstatement of extinguished cocaine-seeking behavior in rats. Psychopharmacology (Berl) 168:57-65.

McLaughlin RJ, Floresco SB (2007) The role of different subregions of the basolateral amygdala in cue-induced reinstatement and extinction of food-seeking behavior. Neuroscience 146:1484-1494.

Myers KM, Davis M (2002) Behavioral and neural analysis of extinction. Neuron 36:567-584.

Paton JJ, Belova MA, Morrison SE, Salzman CD (2006) The primate amygdala represents the positive and negative value of visual stimuli during learning. Nature 439:865-870.

Pavlov IP (1927) Conditioned reflexes: an investigation of the physiological activity of the cerebral cortex. London: Oxford UP.

Paxinos G, Watson C (1998) The rat brain in stereotaxic coordinates. New York: Academic.

Peters J, Vallone J, Laurendi K, Kalivas PW (2008) Opposing roles for the ventral prefrontal cortex and the basolateral amygdala on the spontaneous recovery of cocaine-seeking in rats. Psychopharmacology (Berl) 197:319-326.

Quirk GJ, Mueller D (2008) Neural mechanisms of extinction learning and retrieval. Neuropsychopharmacology 33:56-72.

Quirk GJ, Russo GK, Barron JL, Lebron K (2000) The role of ventromedial prefrontal cortex in the recovery of extinguished fear. J Neurosci 20:6225-6231.

Quirk GJ, Garcia R, González-Lima F (2006) Prefrontal mechanisms in extinction of conditioned fear. Biol Psychiatry 60:337-343.

Repa JC, Muller J, Apergis J, Desrochers TM, Zhou Y, LeDoux JE (2001) Two different lateral amygdala cell populations contribute to the initiation and storage of memory. Nat Neurosci 4:724-731.

Rescorla RA (2001) Retraining of extinguished Pavlovian stimuli. J Exp Psychol Anim Behav Process 27:115-124.

Rescorla RA, Wagner AR (1972) A theory of Pavlovian conditioning: variations in the effectiveness of reinforcement and nonreinforcement. In: Classical conditioning II: current research and theory (Black AM, Prokasy WF, eds), pp 64-99. New York: Appleton-Century-Crofts.

Rosenkranz JA, Moore H, Grace AA (2003) The prefrontal cortex regulates lateral amygdala neuronal plasticity and responses to previously conditioned stimuli. J Neurosci 23:11054-11064.

Saddoris MP, Gallagher M, Schoenbaum G (2005) Rapid associative encoding in basolateral amygdala depends on connections with orbitofrontal cortex. Neuron 46:321-331.

Schoenbaum G, Roesch M (2005) Orbitofrontal cortex, associative learning, and expectancies. Neuron 47:633-636.

Schoenbaum G, Chiba AA, Gallagher M (1998) Orbitofrontal cortex and basolateral amygdala encode expected outcomes during learning. Nat Neurosci 1:155-159.

Sotres-Bayon F, Bush DE, LeDoux JE (2007) Acquisition of fear extinction requires activation of NR2B-containing NMDA receptors in the lateral amygdala. Neuropsychopharmacology 32:1929-1940.

Tremblay L, Schultz W (2000) Modifications of reward expectation-related neuronal activity during learning in primate orbitofrontal cortex. J Neurophysiol 83:1877-1885.

Tye KM, Janak PH (2007) Amygdala neurons differentially encode motivation and reinforcement. J Neurosci 27:3937-3945.

Tye KM, Stuber GD, de Ridder B, Bonci A, Janak PH (2008) Rapid strengthening of thalamo-amygdala synapses mediates cue-reward learning. Nature 453:1253-1257.

Washburn MS, Moises HC (1992) Electrophysiological and morphological properties of rat basolateral amygdaloid neurons in vitro. J Neurosci 12: 4066-4079. 